\title{
Evolution of pile shaft capacity over time in marine soils
}

\author{
Mohammad Amin Hosseini ${ }^{*}$ and Mohammad Rayhani
}

\author{
*Correspondence: \\ amin.hosseini@carleton.ca \\ Geoengineering Research \\ Group, Carleton University, \\ Ottawa, Canada
}

\begin{abstract}
Driven pile foundations may experience an increase in bearing capacity overtime after installation which is referred to as pile set-up or freeze. Field observations have demonstrated that pile set-up could be substantial and the evolution of pile shaft capacity may continue for an extended time after pile installation. This paper presents results of a series of pile load tests conducted on medium-scale steel and concrete pile foundations driven into marine sensitive clay in Gloucester, Ontario. The piles were tested instantly after driving to measure their initial bearing capacities, and were tested repeatedly over different elapsed times to study the evolution of pile shaft capacity over time. The excess pore water pressure around the pile was also monitored by a piezometer. The pile performance analysis was established by monitoring the shaft capacity of driven model piles over 1 month in soft marine clay. The average pile capacity measurements for both steel and concrete piles showed approximately 4.5-5.5 times increase in the pile capacity 30 days after initial driving depending on the type of the piles used.
\end{abstract}

Keywords: Marine clay, Pile shaft capacity, Pile set-up, Pile load test

\section{Introduction}

The bearing capacity of a single pile shows the maximum load a pile can withstand under different modes of loading (compression, tension, lateral, etc.). The axial bearing capacity of a pile, $q$, is normally derived from frictional shaft capacity developed along the pile surface, $q_{s}$, and toe capacity derived from soil resistance under the toe of the pile, $q_{t}$. The contribution of each of these bearing capacity components depends on the type of the soil as well as pile characteristics. The shaft resistance of piles is dependent on the interaction of the pile shaft and adjacent soils as well as the method of installation (i.e., driving, cast-in-place, and screw piling). Pile driving is normally performed using an impact or vibratory hammer depending on the nature of the soil and design regulations. Different types of pile foundations including precast concrete pile, timbers, steel and composite piles can be installed using driving techniques. However, this technique might generate different levels of soil displacement depending on the geometry of the pile during pile driving. This soil displacement may be advantageous in cohesionless soils, as it could densify the surrounding soil and increase the shaft capacity of the pile. In cohesive soils, on the other hand, the pile driving may cause soil disturbance and alter the soil structure around the pile, and induce excess pore water pressure which, in turn,

(c) The Author(s) 2017. This article is distributed under the terms of the Creative Commons Attribution 4.0 International License (http://creativecommons.org/licenses/by/4.0/), which permits unrestricted use, distribution, and reproduction in any medium, provided you give appropriate credit to the original author(s) and the source, provide a link to the Creative Commons license, and indicate if changes were made. 
can reduce the pile capacity. According to De Mello [1], the process of change in soil structure can be divided into four stages. The first stage is the remoulding of the structure of the soil around the pile, which occurs during pile driving. The second stage is the variations in the state of stress of the soil and the pile, which is referred to as the formation of excess pore water pressure. This excess pore water pressure will reduce the effective stress of the soil and, hence, the shear strength of the soil for a specific period of time after driving. The third stage is defined as the dissipation of excess pore water pressure, which occurs at a certain rate depending on the soil permeability. Lastly, it is the increase in the soil strength overtime due to dissipation of the excess pore water pressure, and soil aging.

Excess pore water pressure is developed due to the remoulding and disturbance of soil by driven piles. The excess pore water pressure can approach up to twice the in situ vertical effective stress in soil around the pile, although this can reach up to 3-4 times the effective stress at the toe of the pile [2]. In case of sensitive soils such as Leda clay, the resulting excess pore water pressure could be greater, i.e., up to 8 times of the effective stress [3]. The dissipation of this excess pore pressure starts immediately after the excess pore water pressure build up. This process is accompanied by changes in the stress field of the soil around the pile, where the effective stress of the soil increases as the pore water dissipation proceeds, which in turn leads to reconsolidation of the soil and, hence, increase in shear strength of the affected soil. The shear strength of the reconsolidated soil around driven piles after dissipation was reported to be higher than the soil's initial undisturbed shear strength [2]. The dissipation rate is dependent on soil permeability, pile spacing and material, and thickness of the clay layer.

Pile driven into various types of soils, specifically in clay, experience an increase in capacity as a function of time mainly due to dissipation of excess pore water pressure generated around the pile during pile driving, and reconsolidation and aging of the disturbed soil near the piles. This time-dependent capacity increase is referred to as set-up or freeze. Immediately after driving, the rate of the set-up coincides with the rate of dissipation showing a linear relation which lasts just minutes after driving the pile [4]. A non-linear trend with respect to the time log is typically observed after the initial time at which, the effective horizontal stress increases in the distressed soil and the soil is consolidated and its strength is increased [5]. The duration of phase 2 is a function of soil (type, permeability, and sensitivity) and pile (type, permeability, and size) properties. Based on conventional consolidation theory, a very long time is required for the dissipation of excess pore water pressure to be completed (weeks to years). Essentially, there is a time after which the rate of dissipation is very slow and there would be no additional consequence. At this time, the primary consolidation is typically achieved. However, secondary compression continues immediately after the completion of primary consolidation and is independent of effective stress. At phase 3, aging of the soil will occur which could be related to thixotropy, secondary compression, particle interference, and clay dispersion [6-8]. Aging effects may increase the shear modulus, stiffness, and dilatancy of the soil, and decrease the compressibility of the soil $[8,9]$. In addition, aging may increase the pile-soil interface friction [10] at an approximately linear rate with the $\log$ of time [8]. 
Several previous researchers observed the set-up within 30 days after the pile installation day, and after that, the rate of change was very slow (e.g., [11-15]). The set-up value is related to soil characteristics, pile type and the installation technique. Pile setup occurs in almost all types of soils including organic and inorganic clays, loose to medium dense silts, sandy silts, and fine sands [16, 17]. The set-up in granular soils typically depends on the depth of the ground water table (GWT). Svinkin [18] stated that the rate of set-up is linear with time above GWT, while the set-up with respect to the time is a power function below GWT. The increase in capacity was reported at approximately $100 \%$ over 3 months in non-cohesive soils. In clay soils, the set-up is mainly related to reconsolidation of the disturbed soil around the pile, and aging [2]. Alternatively, pile set-up is also dependent on the driven pile types. The set-up was shown to be affected by the composition of piles (i.e., timber, concrete, steel, and composite piles) and the level of soil displacement induced during pile installation process which can be a function of pile size and type (e.g., H-piles, open-ended pipe piles, and closed-end pipe piles).

Although, this rich literature provides an insight to the subject of the pile set-up, but the exact mechanism of set-up is not fully clear, and the pile set-up has not been incorporated in the current design practice. In this study, the rate and magnitude of set-up for driven piles in sensitive soils is investigated using medium-scale pile load tests installed in Leda clay, while monitoring the pore water pressure around the pile.

\section{Test site characteristics}

Pile load tests were conducted in the "Canadian Geotechnical Research Site No. 1 " located at Gloucester, Ontario, Canada. This site has been traditionally used for measuring the behaviour of deep compressible clay layers [19]. The soil in this site is a type of marine sensitive clay called Leda clay which covers Ottawa Valley and south of Province of Quebec in Canada. This clay was formed near the end of the most recent glaciation period in the pre-historic Champlain Sea. The soil unit weight was measured to be about $15.3 \mathrm{kN} / \mathrm{m}^{3}$ and the water content of the soil was measured at about 52\% (referred to ASTM D2216 [20]). From the Atterberg limit tests, the plasticity index of this clay was determined at approximately $24 \%$ with a liquid limit of 51\% (referred to ASTM D4318 [21]). Vane shear tests were performed according to ASTM D2573 [22] to determine the average undrained shear strength which was estimated to be about $35 \mathrm{kPa}$. The coefficient of one-dimensional consolidation was measured according to ASTM D2435/2435M [23] at a value of $1.4 \times 10^{-8} \mathrm{~m}^{2} / \mathrm{s}$. A direct shear box testing program according to ASTM D6528 [24] was also performed on intact clay specimens in order to determine its drained and undrained shear strength parameters (Table 1).

Table 1 Index properties of Leda clay in Canadian Geotechnical Research Site No. 1

\begin{tabular}{llllllll}
\hline $\mathbf{\rho}\left(\mathbf{M g} / \mathbf{m}^{\mathbf{3}}\right)$ & $\mathbf{W}(\%)$ & LL (\%) & $\mathbf{P I}(\%)$ & $\mathbf{S u}(\mathbf{k P a})$ & $\mathbf{C}^{\prime}(\mathbf{k P a})$ & $\boldsymbol{\Phi}^{\prime}\left({ }^{\circ}, \mathbf{d e g}\right)$ & $\mathbf{C v}\left(\mathbf{m}^{\mathbf{2} / \mathbf{s})}\right.$ \\
\hline 1.53 & 52 & 51 & 24 & 35 & 8.6 & 26 & $1.40 \times 10^{-8}$ \\
\hline
\end{tabular}




\section{Experimental procedure}

\section{Test setup}

Three common types of pile including precast concrete, closed-end steel and openended steel pipe piles with outside diameter of approximant $100 \mathrm{~mm}$ and embedment length of $2.0 \mathrm{~m}$ were used to perform pile load test. All three piles had a steel encasing system at the pile head with the aim to apply the axial load and prevent pile head damage during driving (Fig. 1).

The area at the site was scrapped approximately $1 \mathrm{~m}$ below the surface to remove the top soil and expose the undisturbed clay for testing. The model piles were driven to an embedment depth of $2 \mathrm{~m}$ while their spacing was kept at five times pile diameter to prevent group effects on load transfer of the piles [25,26]. A pile load testing frame was assembled at the test site to apply the axial load on model piles. The frame designed to act as the reaction beam for pile load tests, and provide sufficient strength against applied load with minimal deflection (Fig. 2). The horizontal reaction beams were assembled using two $10 \times 2$ lumber beams bolted to two open-ended steel reaction piles with a diameter of $152.4 \mathrm{~mm}$ and height of $3.0 \mathrm{~m}$ driven at a distance of approximately $3.0 \mathrm{~m}$ to form the pile load test frame.

\section{Pile installation}

Pile driving was performed using a pulley which was attached on top of a tripod and drop hammer setup. The drop hammer had a weight of $88 \mathrm{lb}(40 \mathrm{~kg})$ at an average dropping height of $400 \mathrm{~mm}$ which was kept constant during the pile load test. The impact energy generated by the hammer drop was about $78.5 \mathrm{~J} / \mathrm{blow}$. Pile driving was performed at approximately 10-15 blows per minute, generating a penetration of $1-2 \mathrm{~mm} /$ blows at shallow depths to as high as $5 \mathrm{~mm} / \mathrm{blow}$ while attaining the target depth. Cumulative number of blows versus depth ratio indicated that open-ended steel pile resisted more than closed-end steel pile which this may be due to soil plug in the open-ended steel pile (Fig. 3).

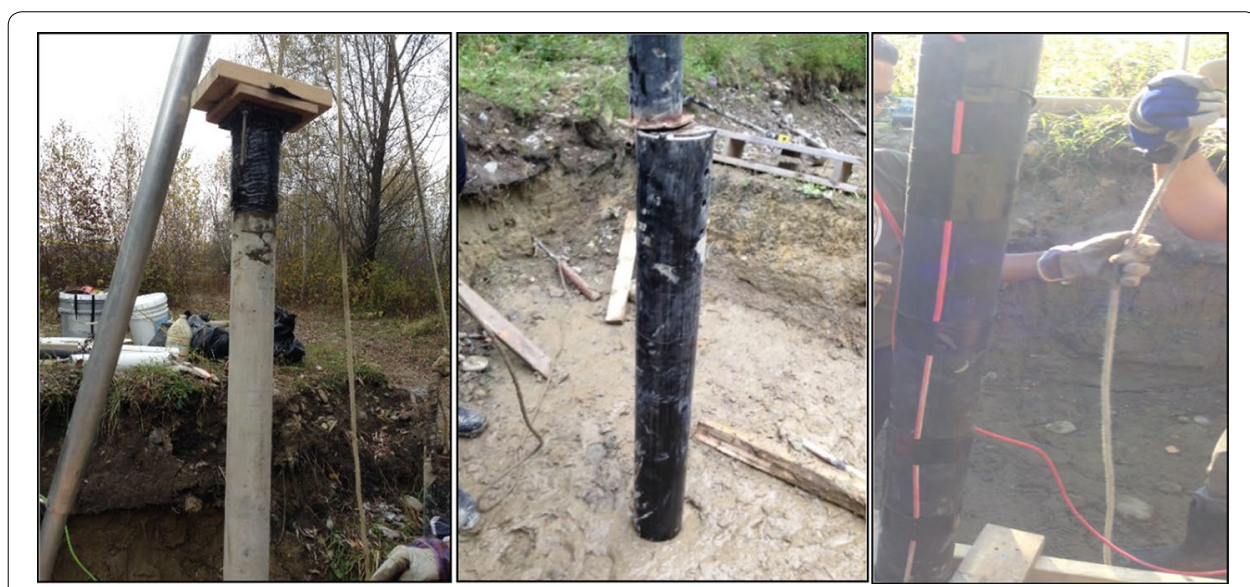

Fig. 1 Model piles (from left to right: precast concrete pile, open-ended steel pile, and closed-end steel pile) 


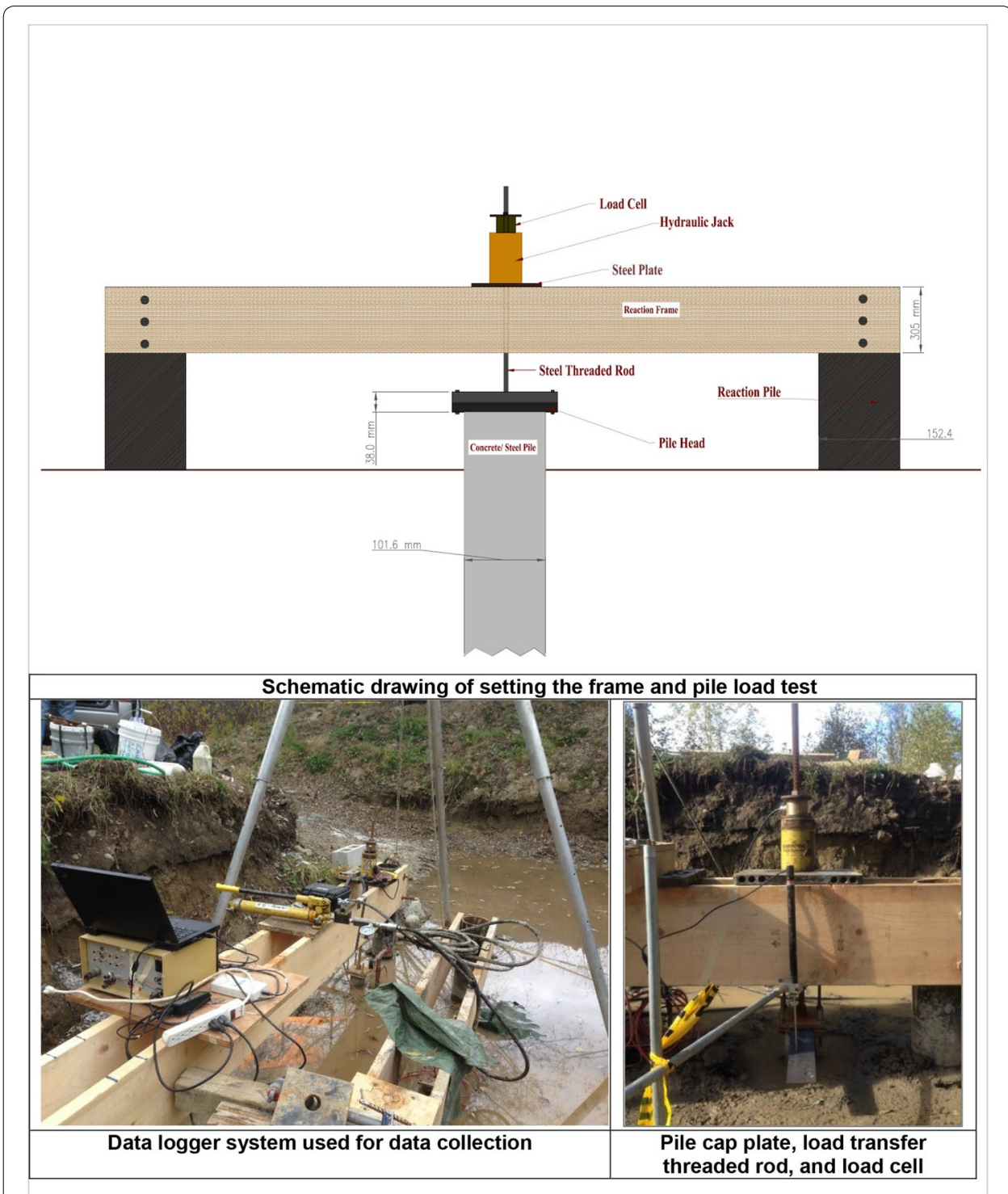

Fig. 2 Setting the frame and pile load test in Canadian Geotechnical Research Site No. 1

\section{Pile load tests}

The pile loading test was performed under tension to measure the pile shaft capacity according to ASTM D3689 [27]. The pile head mechanism was used to connect a steel rod to the hydraulic jack and reaction frame allowing for the application of pullout loads. The load was applied using a hydraulic jack and the applied load was measured through a calibrated load cell system placed at the jack, while the displacement of the pile was monitored with a displacement transducer (LVDT).

The loading procedure was designed to reach failure by applying incremental loading at $60 \mathrm{~s}$ intervals. This allowed the interface force to reach the equilibrium. Immediately after each test, the pressure from hydraulic jack was released to avoid excessive soil disturbance. The failure principle used to distinguish the ultimate shaft capacity over time was pile load carrying capacity at pile head displacement of $10 \%$ pile diameter as 


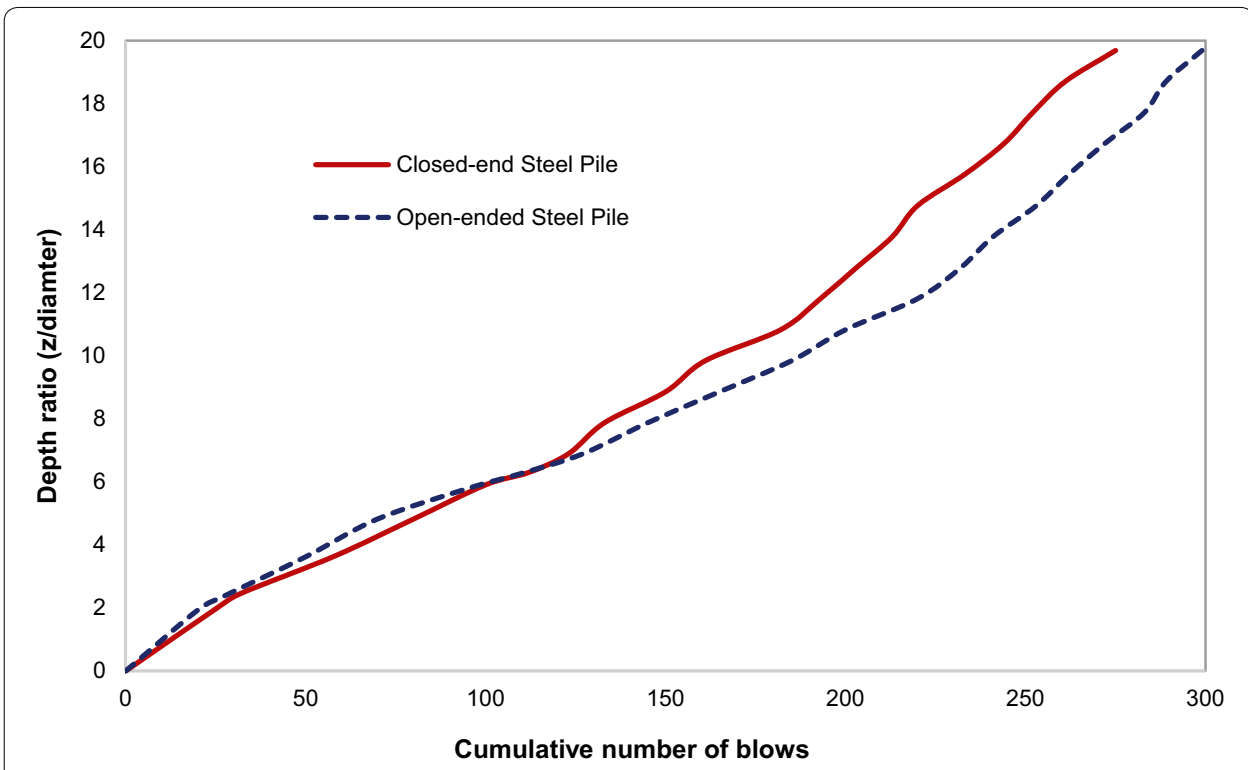

Fig. 3 Depth ratio versus cumulative number of blows

suggested by [28]. The pile loading was performed at a displacement rate of $5 \mathrm{~mm} / \mathrm{min}$ immediately after driving and repeated $1,3,7,14$, and 30 days after initial driving. It should be noted that pile load tests normally are not repeated on one pile in field. However, this procedure was applied here to avoid the impact of other variables (pile properties, soil variations, etc) on the pile capacity change.

Distribution of pore water pressure in the pile surrounding soil is an important factor to understand the increase in pile capacity over time. Therefore, a vibrating wire piezometer with pressure capability of $0.7 \mathrm{MPa}$ was installed close $(25 \mathrm{~mm})$ to the concrete pile toe in order to monitor the variation of pore water pressure while driving till the end of initial driving (EOID) as well as testing at different elapsed times as shown in Fig. 4 (1, 3, 7,14 , and 30 days).

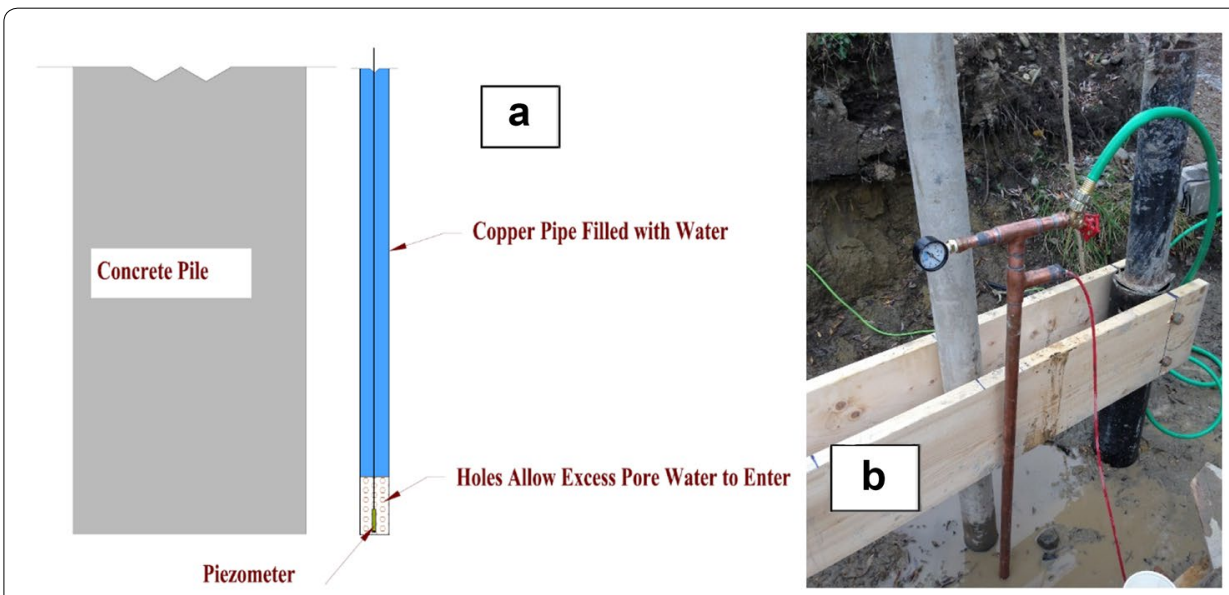

Fig. 4 a Schematic drawing of driven piezometer adjacent to the concrete pile $\mathbf{b}$ piezometer system adjacent to the pile in test site 


\section{Results and discussions}

\section{Evolution of pile capacity over time}

Figure 5 shows the tensile load-displacement curves for pile load tests conducted on model piles at the end of initial driving (EOID) as well as 1, 3, 7, 14, and 30 days after the EOID. The initial shaft capacity for the concrete pile (Fig. 5a) was measured at about $990 \mathrm{~N}$, and eventually reached $6.16 \mathrm{kN}$ after 30 days after initial driving. The rate of increase in pile shaft capacity was higher in the earlier stages changing from day 0 to day 1 and day 3. This rate, however, was much less for the time period of 3-30 days after EOID. This could be related to significantly higher rate of excess pore water pressure dissipation in the earlier stages, which led to significant increase in pile shaft capacity increasing from an initial value of about $1-4.8 \mathrm{kN}$ only 3 days after initial driving.

The initial shaft resistance for the closed-end pipe pile was measured at $945 \mathrm{~N}$ and slightly increased to $1.1 \mathrm{kN}$ one day after the EOID. The rate of increase between day 1 and day 3 was significantly higher increasing up to $5.1 \mathrm{kN}$ three days after initial testing. Similar to the concrete pile, the rate of change in shaft capacity between day 3 and day 30 was not so significant, which could similarly be related to the difference in rate of dissipation of excess pore water pressure around the pile (Fig. 5b). For the open-ended steel pile, the shaft capacity was measured to be $969 \mathrm{~N}$ initially after driving, and increased to 2.45 one day after driving (Fig. 5c). The ultimate capacity of the pile was measured at $5.96 \mathrm{kN}$ at day 7 , and reached a steady state and almost constant capacity afterward. The rate of set-up was found to be similar to the other piles tested here, in which, the rate of increase in shaft capacity was higher in the earlier stages (day 1-7) and slowed afterwards. This may correlate to the rate of excess pore water pressure dissipation. As discussed earlier, there is a period of time after the primary consolidation in which the change in the rate of set-up is very slow (secondary compression). The shaft capacity measured 14 and 30 days after the EOID slightly decreased from the maximum values measured 7 days after the EOID. This could be related to the repeated shearing during load tests on the same pile which could have further disturbed the pile-soil interface and slightly reduced the ultimate pile capacity.

The ultimate shaft capacity of precast concrete pile is almost $10 \%$ higher than the other two piles. This can be related to possible water absorbance in concrete materials which it in turn facilitates the dissipation of excess pore water pressure and accordingly increase the shaft capacity (i.e., concrete can absorb some of the surrounding pore water). However, in general, all the piles revealed a similar evolution trend in shaft capacity.

\section{Variation of pore water pressure around the pile}

In order to examine the change in pore water pressure during pile driving and static load testing, the pore water pressure (PWP) was monitored using a piezometer close to the pile toe. Excess pore water pressure is developed due to remoulding and disturbance of the soil by driven piles. According to the relationship between effective stress and pore water pressure, when a pile is driven into the soil, total stress is increased as the pile pushes the soil away and changes the structure of the surrounding soil. In this case, the soil generates excess pore water pressure, which in turn leads to decrease in the effective stress. The change in pore water pressure over time was recorded and the result is presented in Fig. 6. During pile driving, the pore water pressure around the pile increased 


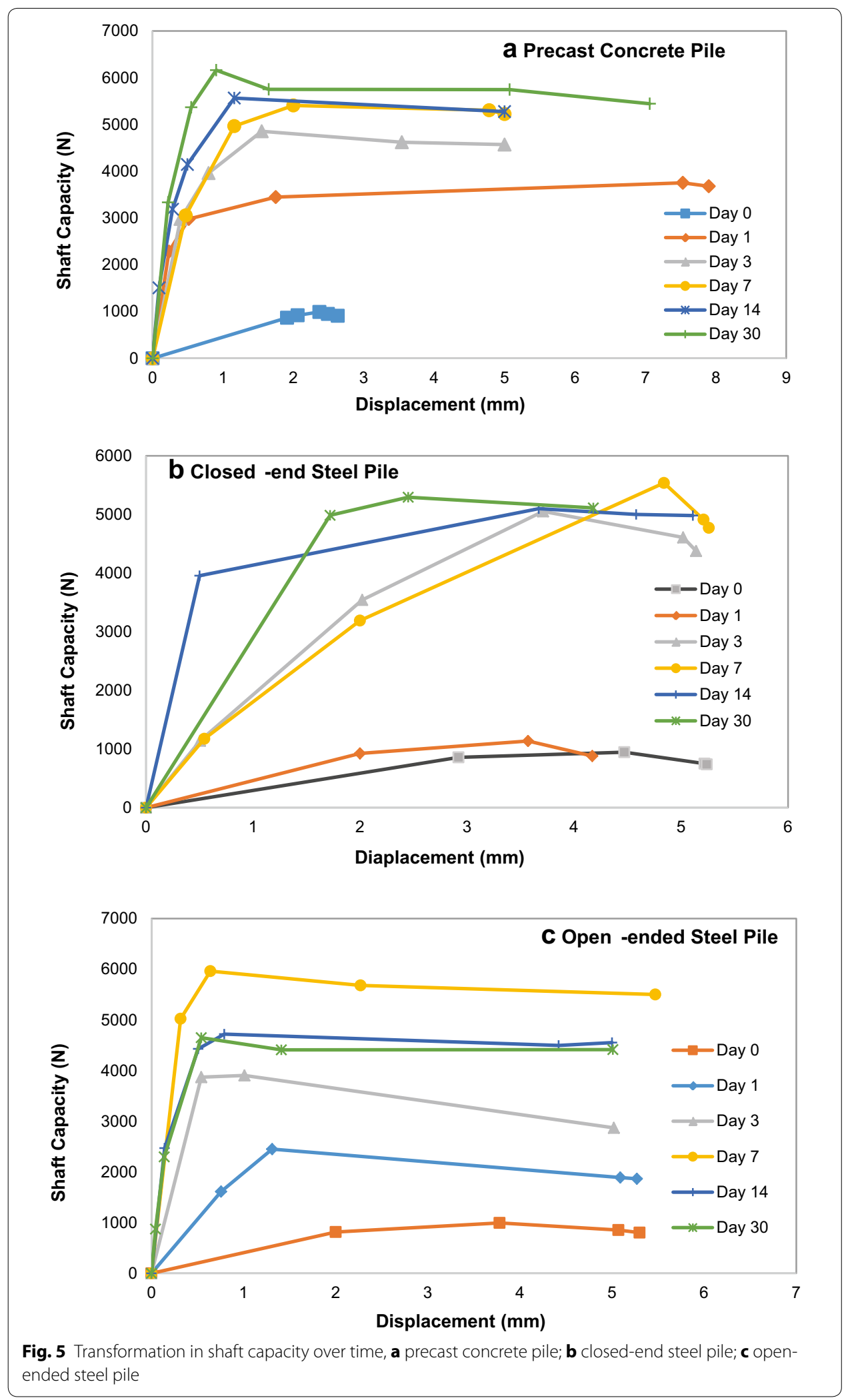




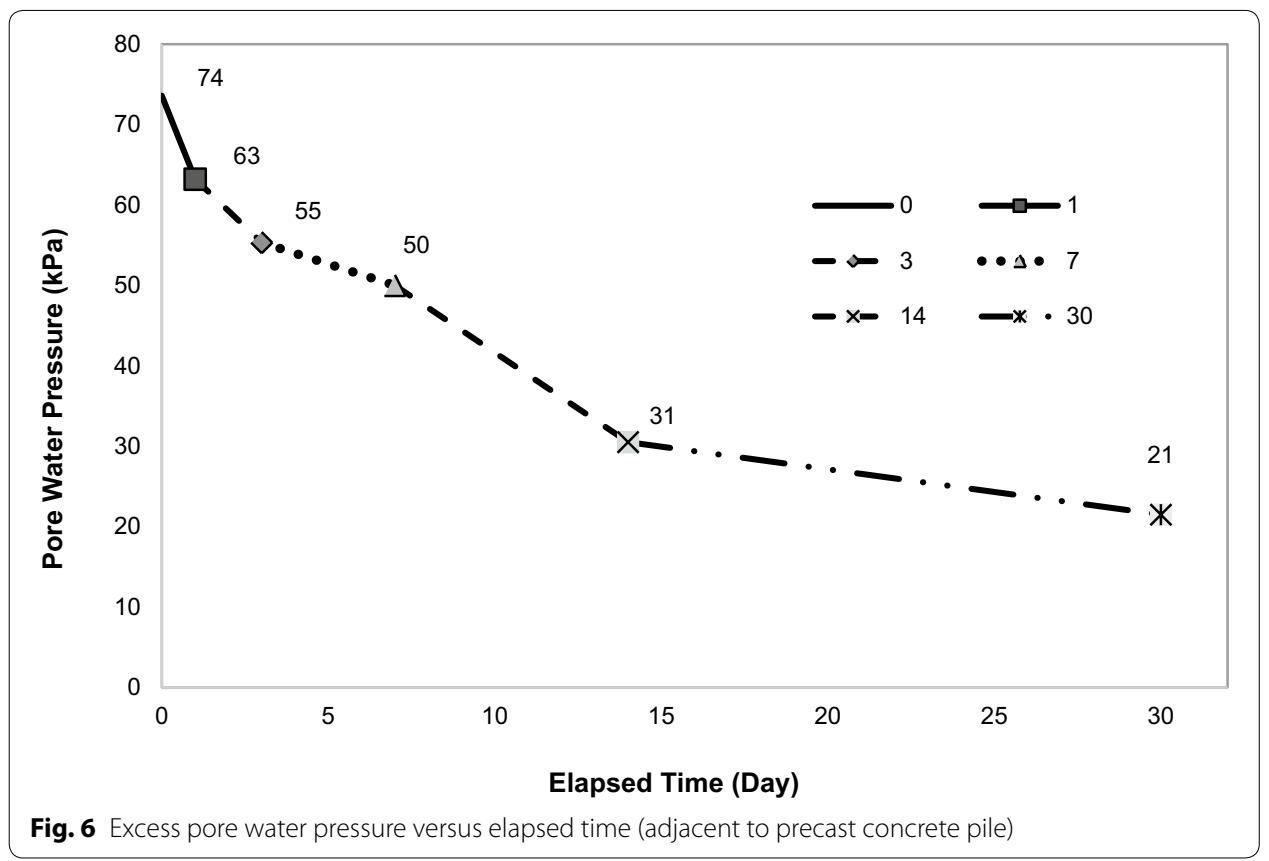

and eventually an excess pore water pressure of $70 \mathrm{kPa}$ was recorded by the sensor installed at the toe of the piezometer. The PWP recording was continuously repeated during every test over elapsed time of $1,3,7,14$, and 30 days after the EOID. The results show that the PWP began to decrease due to dissipation until it reached a value of $22 \mathrm{kPa}, 30$ days after the EOID. This result demonstrates the relationship between PWP dissipation and evolution of pile shaft capacity over time.

The pore water pressure builds up around the pile can be estimated by cavity expansion theory using the undrained shear strength and the shear modulus of the soil [29]. Using this theory, the maximum excess pore pressure around the pile surface would be about three times the undrained shear strength of the soil $(\mathrm{Su})$, which will lead to an excess pore water pressure value of $105 \mathrm{kPa}$. The maximum excess pore water pressure value measured in this experiment is slightly lower than what was proposed by this method $(70 \mathrm{kPa})$, which could partly be related to the location of the pore pressure sensor that was located at a distance of $25 \mathrm{~mm}$ from the surface of the pile. The difference can also be explained by the fact that the excess pore pressures predicted by the cavity expansion theory may be overestimated, due to not following the correct strain path [30, $31]$.

\section{Mechanism of set-up}

The gain in pile capacity is analyzed by two phenomena of primary consolation and secondary consolidation. The sudden increase of shaft capacity is often linked to primary consolidation at initial times (day 0 up to day 7). Pile driving induces disturbance and alters the structure of the clay surrounding the pile, leading to development of excess pore water pressure as a result of soil disturbance. The increase in pore water pressure results in reduction of effective stress in the pile surrounding soil and, hence, decreases the pile-soil interface shear strength. On the other hand, immediately after pile driving, 
this generated excess pore water pressure starts to dissipate rapidly. The rate of decrease in pore water pressure due to dissipation is dependent on pile characteristics such as diameter and materials, as well as soil permeability. Similarly, the rate of increase in shaft capacity is proportional to the rate of decrease in pore water pressure as shown in Figs. 5 and 6 . The rate of dissipation of the excess pore water pressure and, hence, the rate of increase in shaft capacity began to decline about 3 days after initial driving.

These results underscore the importance of excess pore water pressure in reducing the ultimate pile capacity by reducing the mean effective stress during shearing at the pile-soil interface level. The slight increase in pile shaft capacity, after dissipation of the excess pore water pressure, is mainly related to soil aging (secondary compression), since the effective stress-related set-up is adequately completed and, hence, the rate of set-up is independent of effective stress during this phase [32].

\section{Duration of set-up}

The pile set-up process may also be explained using Terzaghi's theory for one-dimensional consolidation in the pile surrounding soil. As per this theory, the time required for dissipation of excess pore water pressure, and hence the capacity increase, may be estimated using radial consolidation solution of Randolph and Wroth [33]:

$$
T=\frac{c_{h} t}{d^{2}}
$$

where $t$ is the time, $d$ is the diameter of pile, and $c_{h}$ is an appropriate coefficient of consolidation of the soil. At the consolidation stage, soils that are located around the pile at a distance of approximately 3-5 times the pile radius, experiences consolidation [32]. Using this expression, the time of consolidation of the disturbed zone for the mediumscale piles used here was estimated to be approximately 8 days under the assumption that pore water pressure is uniformly distributed within the remoulded soil around the pile. However, the dissipation of pore water pressure was observed to be longer in this experiment, though most of changes in PWP occurred in the first 7 days. The difference in the predicted and measured dissipation time could be related to the location of the pore water pressure sensor, which was located about $25 \mathrm{~mm}$ away from the pile surface, or limitation of the approximation method proposed by Randolph and Wroth [33].

\section{Magnitude of pile set-up in marine clays}

Developing a prediction equation to estimate pile set-up, and consequently the ultimate capacity of the design piles, can significantly reduce the construction cost through modifying the pile size, the embedment depth, and number of piles. Several researchers have broadly supported Skov and Denver's [34] prediction equation to estimate the bearing capacity of piles at a particular time considering the pile set-up. This particular empirical relationship can predicate set-up linearly with respect to log of time.

$$
\frac{Q}{Q_{0}}=A \log _{10}\left(\frac{t}{t_{o}}\right)+1
$$

The bearing capacity $Q$ at time $t$ after the end of driving is contributed to an anticipated initial time, also called reference time $t_{o}$, and initial pile capacity $Q_{o} . A$ is a dimensionless 
constant value used to characterize the pile and soil. The time $t_{o}$ is typically assumed to be the point where the dissipation of pore water pressure shows a linear trend with respect to $\log$ of time $[4,34,35]$. Based on a case study of 13 driven piles and almost 21 pile load test data, Skov and Denver [34] proposed a value of $A=0.6$ and $t_{0}=1$ day for clay. From the data that was obtained from this field tests, a range of set-up parameter $A=1.5-3.5$, can be suggested for this sensitive marine clay for an elapsed time of 1 day to 1 month. The pile capacity at different elapsed times may be estimated using this parameter and Eq. (2). This approach may be used as an approximate approach in the design of pile foundations to predict potential magnitude of pile bearing capacity in marine sensitive clays. However, the application of these parameters will be limited to specific conditions as these values could vary significantly depending on site conditions and characteristics of piles used in different projects.

Steward and Wang [36] proposed an expression considering both the effect of aging and dissipation of pore pressure. This method is used to evaluate the pile capacity assuming that the gain in strength due to aging only increases the soil friction rather cohesion of the soil [8]:

$$
f(s)=\mathrm{K}\left[\sigma_{v}-\mathrm{u}(\mathrm{t})\right] \tan \emptyset_{R}^{\prime}
$$

where $\emptyset_{R}^{\prime}$ is the friction angle in drained condition; $K$ is the coefficient of lateral earth pressure at rest; $\sigma_{v}$ is vertical stress, and $\mathrm{u}(\mathrm{t})$ is expressed as the pore water pressure over elapsed time.

Equation (3) can be used to predict the frictional capacity using the measured/predicted remoulded friction angle. From the field test data here, the frictional resistance of the concrete pile was approximately $0.76 \mathrm{kPa}$ and the estimated frictional resistance using Eq. (3) was about $2.7 \mathrm{kPa}$. It seems that this approach overestimates the shaft capacity for medium-scale piles, even though, the actual shaft capacity may be slightly higher since the excessive loading of the pile over time may have affected the maximum capacity that the pile might reach.

\section{Comparison with past studies}

Several researchers investigated the pile set-up in marine soils (e.g., [11, 37, 38]). Afshin and Rayhani [11] investigated the pi set-up in Leda clay by performing a series of small-scale pile load tests in steel drums ( $876 \mathrm{~mm}$ in height and $579 \mathrm{~mm}$ in diameter) in the lab. They reported an average set-up value of 2 after 12 days from initial pile driving. In general, the rates of set-up obtained from the laboratory tests conducted by Afshin and Rayhani [11] and those measured in the field seem to be similar. However, the magnitudes of set-up in the field are significantly higher than those measured in the lab. This difference could be due to the difference in overburden pressure and the state of stress in both experiments.

The average set-up value measured in this study is compared with some of the past results for driven piles in clay (Fig. 7). The set-up rate for the piles investigated here shows a consistent trend with the results of past studies. However, marginal alteration may occur mainly due to the soil properties, and also the level of the disturbance and remoulding during driving the piles due to variation in pile geometry and soil characteristics. 


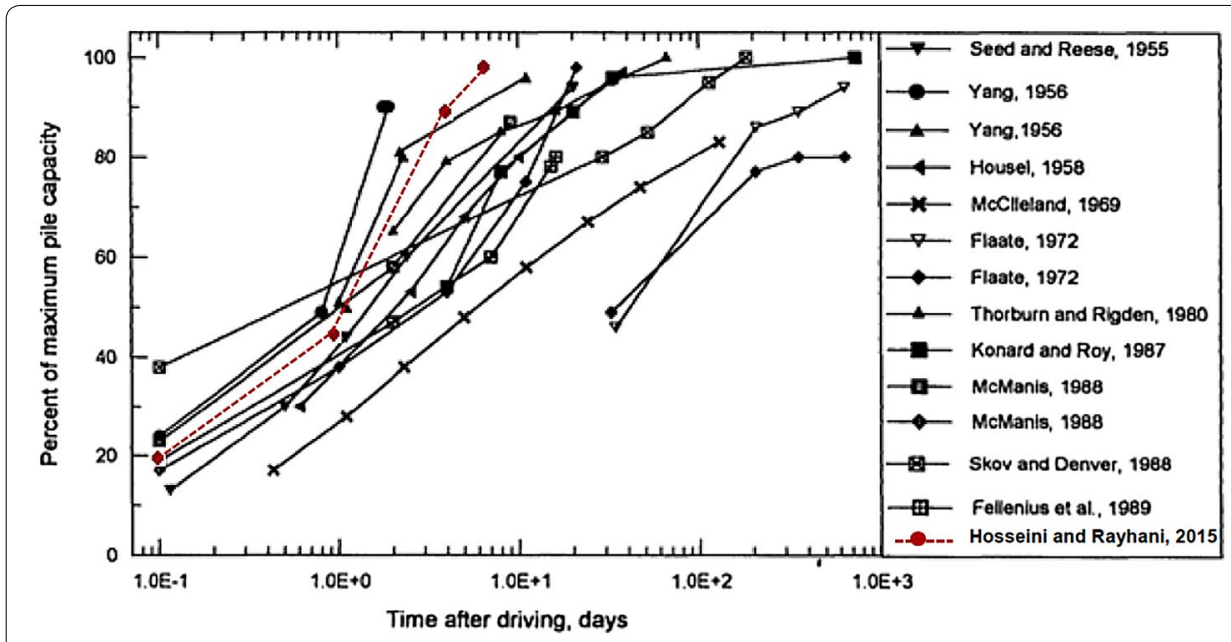

Fig. 7 Pile capacity increase with time for piles driven into clay (modified after [39])

\section{Contribution of pile set-up in design}

Several methods (e.g., Canadian Foundation Engineering Manual) are currently used to estimate pile capacity as a function of the pile geometry and the interface resistance of pile-soil for pile design. For total stress analysis, the pile shaft resistance is typically estimated based on the undrained shear strength $\left(S_{u}\right)$ of the soil and an empirical adhesion coefficient $(\alpha)$.

$$
q_{s}=S_{u} \alpha
$$

The undrained shear strength, $\mathrm{S}_{\mathrm{u}}=35 \mathrm{kPa}$ for Leda clay was obtained from vane shear test and this value is used to calculate the design shaft resistance. In addition, the empirical adhesion coefficient $(\alpha)$ is estimated from a reverse calculation using the undrained shear strength and it is approximately 0.44 for the initial shaft capacity at the EOID. Table 2 lists the measured pile capacity of all three piles which were tested in tension and also presents the calculated pile capacity using $\alpha$-Method. The estimated shaft capacity for all three piles is almost 1.5 times the initial measured capacity which was obtained immediately after driving the piles. However, it can be seen that the capacity increased up to 5 times from their initial capacity after 30 days. These results underscore the importance of considering the pile set-up in pile design. Consequently, the implementation of the set-up in design can reduce the number of piles and/or the embedment depth, which would reduce the cost of the construction.

Table 2 Summary of measured and estimated shaft resistance

\begin{tabular}{lllll}
\hline Pile type & \multicolumn{2}{l}{ Measured shaft resistance (N) } & $\begin{array}{l}\text { Estimated shaft } \\
\text { resistance (N) }\end{array}$ & Rate of increase \\
\cline { 2 - 4 } & Initial (day 0) & Day 30 & & \\
\hline Precast concrete & 990 & 6162 & 1479 & 4.2 \\
Closed-end steel & 969 & 4650 & 1435 & 3.2 \\
Open-ended steel & 945 & 5295 & 1412 & 3.7 \\
\hline
\end{tabular}


Using measured shaft capacity for the model piles, the range of $\beta$ parameter used in the effective stress analysis of the piles in practice can also be estimated. The unit shaft resistance is expressed in terms of the effective overburden pressure $\left(\sigma_{v}^{\prime}\right)$ and an empirical interface coefficient $(\beta)$ which is shown in following expression:

$$
q_{s}=\beta \sigma_{v}^{\prime}=K_{s} \tan \delta \sigma_{v}^{\prime}
$$

Table 3 presents the estimated $\beta$ values over time using unit shaft resistance measured at the field and the average effective stress, $\sigma_{\mathrm{v}}{ }^{\prime}$ (i.e., $\left.\sigma_{v}^{\prime}=\gamma^{\prime} z=(15.3-9.81) \times 1=5.5 \mathrm{kPa}\right)$. As shown, the $\beta$ value is approximately at the range of $0.270-0.28$ for all three piles when tested immediately after driving. Taking into account the evolution of pile capacity over time, the $\beta$ value increased up to $1.3-1.7$, 30 days after initial driving. This further underscores the importance of considering the pile set-up in design of driven piles in clay.

\section{Conclusions}

A series of pile load tests were carried out on model scale piles including precast concrete, closed-end steel pipe pile and open-ended steel pipe pile driven into a marine sensitive clay in Gloucester, ON, Canada. The measurements include tensile load tests which were performed on all three model piles immediately after driving and repeatedly at elapsed times $1,3,7,14$, and 30 days after initial driving. The shaft capacity of all three piles initially was at about $945-990 \mathrm{~N}$. For the pile load tests conducted 14 days after the initial driving, the load carrying capacity for all three piles increased approximately 4.5-5.5 times in average from their initial capacity. The lowest and highest set-up values (30 days after driving) were in the range of 4-6 times for the open-ended steel pile and precast concrete pile, respectively. The rate of increase in pile capacity was significant in the first couple of days from the initial pile driving. This rate was ultimately decreased as the elapsed time increased up to 30 days. These changes could be due to quick dissipation of excess pore water pressure and possibly greater rate of consolidation of the soil in earlier periods. However, when the change in the rate of set-up is very slow, this is correlated to the aging phase (secondary compression), since the effective stress-related set-up is adequately complete and, hence, the rate of set-up is independent of effective stress during this phase.

Table $3 \beta$ values estimated from measured shaft capacity

\begin{tabular}{|c|c|c|c|c|c|c|}
\hline \multirow{2}{*}{$\begin{array}{l}\text { Pile } \\
\text { Time (day) }\end{array}$} & \multicolumn{2}{|c|}{ Precast concrete pile } & \multicolumn{2}{|c|}{ Open-ended steel pile } & \multicolumn{2}{|c|}{ Closed-end steel pile } \\
\hline & $\beta$ value & Ks & $\beta$ value & Ks & $\beta$ value & Ks \\
\hline 0 & 0.28 & 0.63 & 0.276 & 1.57 & 0.269 & 1.53 \\
\hline 1 & 1.07 & 2.01 & 0.698 & 3.49 & 0.324 & 1.62 \\
\hline 3 & 1.38 & 2.96 & 1.57 & 6.44 & 1.44 & 5.90 \\
\hline 7 & 1.58 & - & 1.70 & - & 1.58 & - \\
\hline 14 & 1.59 & 3.66 & 1.35 & 4.77 & 1.45 & 5.12 \\
\hline 30 & 1.76 & - & 1.33 & - & 1.51 & - \\
\hline
\end{tabular}


The experimental results of medium size pile load tests demonstrated the importance of set-up phenomenon in pile design. However, the presented results are based on a limited number of pile load tests. A vast experimental pile load test that involves variation of effective parameters in set-up phenomenon, such as pile size, is required in order to reach a more accurate picture and create an empirical formulation for all type of piles with variety of geometries and materials.

\section{Abbreviations}

A: dimensionless constant value; $C^{\prime}$ : cohesion; $C_{h}$ : lateral coefficient of consolidation; $C v$ : coefficient of consolidation; $d$ : diameter of pile; LL: liquid limit; PI: plasticity index; $q_{s}$ : shaft resistance; $q_{t}$ : toe/base resistance; Su: undrained shear strength; $t_{0}$ : iitial time; $t$ : time; $w$ : moisture content; $\rho$ : density; $\Phi^{\prime}$ : friction angle; $\emptyset_{R}^{\prime}$ : friction angle in drained condition; K: coefficient of lateral earth pressure at rest; $\sigma_{v}$ : vertical stress; $u(t)$ : pore water pressure over elapsed time; Qo: initial pile capacity; $Q$ : bearing capacity at time $t$ after the end of driving; $\alpha$ : adhesion coefficient; $\sigma_{V}^{\prime}$ : effective overburden pressure; $\beta$ : interface coefficient.

\section{Acknowledgements}

This study was financially supported by the Natural Sciences and Engineering Research Council of Canada (NSERC).

\section{Publisher's Note}

Springer Nature remains neutral with regard to jurisdictional claims in published maps and institutional affiliations.

Received: 16 December 2016 Accepted: 28 June 2017

Published online: 06 July 2017

\section{References}

1. De Mello VFB (1969). Foundations of buildings on clay, State-of-the-Art report. In: Proceedings of 7th ICSMFE, pp 49-136

2. Randolph MF, Carter JP, Wroth CP (1979) Driven piles in clay-the effects of installation and subsequent consolidation. Geotechnique 29(4):361-393

3. Poulos HG, Davis EH (1980) Pile foundation analysis and design. Wiley, Hoboken

4. Bullock PJ (1999). Pile friction freeze: a field and laboratory study, vol 1, Ph.D. Dissertation, University of Florida

5. Komurka VE, Wagner AB, Edil TB (2003) Estimating soil/pile set-up, USA WHRP Report No 03-05, Wisconsin Department of Transportation

6. CampllI WM, Wright WB Hussein M (1993) The effect of overburden of pile capacity in a Calcareous Marl. In: Deep foundations institute 18th annual members' conference, pp 23-32

7. Long JH, Kerrigan JA, Wysockey MH (1999) Measured time effects for axial capacity of driven piling. J Transp Res Board 1663:8-15

8. Schmertmann JH (1991) The mechanical ageing of soils. J Geotech Eng 117(9):1288-1330

9. Axelsson G (1998) Long-term setup of driven piles in non-cohesive soils. Licentiate Thesis, Royal Institute of Technology, Stockholm

10. McVay MC, Schmertmann J, Townsend F, Bullock P (1999). Pile friction freeze: a field and laboratory study, Research Report No

11. Afshin A, Rayhani MT (2015) Evaluation of pile shaft capacity increase over time in Leda clay using small-scale pileload tests. Int J Geotech Eng 9(3):307-315

12. Bozozuk M, Fellenius BH, Samson L (1978) Soil disturbance from pile driving in sensitive clay. Can Geotech J 15:346-361

13. Fellenius BH, Samson L (1976) Testing of drivability of concrete piles and disturbance to sensitive clay. Can Geotech J 13:139-160

14. Orrje O, Broms B (1967) Effects of pile driving on soil properties. J Soil Mech Found Div 93(SM5):59-73

15. Seed HB, Reese LC (1955) The action of soft clay along friction piles. In: Proceedings, ASCE, vol 81, Paper no 842

16. Asted B, Weiner $L$, Holm G (1992) Increase in bearing capacity with time for friction piles in silt and sand. In: Proceedings of Nordic geotechnical, pp 411-416

17. Hannigan PJ, Goble GG, Likins GE, Rausche F (1997) Design and construction of driven piles foundations. Publication no. FHWA-HI-97-014, Washington, DC

18. Svinkin MR (1996) Setup and relaxation in glacial sand discussion. J Geotech Eng 122(4):319-321

19. McRostie GC, Crawford CB (2001) Canadian geotechnical research site no. 1 at gloucester. Can Geotech J 38(5):1134-1141

20. ASTM D2216 (2008) Standard test methods for laboratory determination of water (moisture) content of soil and rock by mass. ASTM, West Conshohocken, PA, USA

21. ASTM D4318 (2008) Standard test method for liquid limit, plastic limit, and plasticity index of soils, ASTM Standard 04-08, 1-13. ASTM, West Conshohocken, PA, USA 
22. ASTM D2573 (2008) Standard test methods for field vane shear test in cohesive soils, ASTM Standard 04-08. ASTM, West Conshohocken, PA, USA

23. ASTM D2435/2435M (2011) Standard test method for one-dimensional consolidation properties of soils using incremental loading. ASTM, West Conshohocken, PA, USA

24. ASTM D6528 (2007) Standard test method for consolidated undrained direct simple shear testing of cohesive soils. ASTM, West Conshohocken, PA, USA

25. Franke E (1988) Group action between vertical piles under horizontal loads. In: Van Impe WF, Balkema AA (eds) J Geotech Eng, ASCE, Rotterdam, 119(12), pp 1952-1973

26. Tomlinson MJ (1994) Pile design and construction practice. Chapman and Hall Published, London

27. ASTM D3689 (2010) Standard test methods for deep foundations under static axial tensile load. ASTM, West Conshohocken, PA, USA

28. De Nicola A, Randolph MF (1993) Tensile and compressive shaft capacity of piles in sand. J Geotech Eng 119(12):1952-1973

29. Gibson RE, Anderson WF (1961) In situ measurement of soil properties with the pressuremeter. Civ Eng Public Works Rev 56:615-618

30. Baligh MM (1986) Undrained deep penetration, I: shear stresses. Geotechnique 36(4):471-485

31. Baligh MM (1986) Undrained deep penetration II: pore pressures. Geotechnique 36(4):487-501

32. Randolph MF (2003) Science and empiricism in pile foundation design. Geotechnique 53(10):847-875

33. Randolph MF, Wroth CP (1979) An analytical solution for the consolidation around a driven pile. Int J Numer Anal Methods Geomech 3:217-229

34. Skov R, Denver H (1988) Time-dependence of bearing capacity of piles. In: 3rd International conference on applications of stress wave theory to piles, ISSMFE and Canadian geotechnical society, Ottawa, Canada

35. Axelsson G (2000) Long-term set-up of driven piles in sand. PhD Thesis, Royal Institute of Technology, Stockholm

36. Steward E, Wang $X$ (2011) Predicting pile setup (freeze): a new approach considering soil aging and pore pressure dissipation. In: Geo-frontiers congress 2011, March 13-16, Dallas, Texas, United States, pp 11-19

37. Blanchet R, Tavenas F, Garneau R (1980) Behaviour of friction piles in soft sensitive clays. Can Geotech J 17(2):203-224

38. Yin Z, Karstunen M, Chang C, Koskinen M, Lojander M (2011) Modeling time-dependent behavior of soft sensitive clay. J Geotech Geoenviron Eng 137(11):1103-1113

39. Titi HH (1996) The increase in shaft capacity with time for friction piles driven into saturated clay. ProQuest Dissertation and Theses (PQDT)

\section{Submit your manuscript to a SpringerOpen ${ }^{\odot}$ journal and benefit from:}

- Convenient online submission

- Rigorous peer review

- Open access: articles freely available online

- High visibility within the field

- Retaining the copyright to your article

Submit your next manuscript at $>$ springeropen.com 